\title{
Comparison of two ice-core chemical records recovered from the Qomolangma (Mount Everest) region, Himalaya
}

\author{
HOU Shugui, ${ }^{1 *}$ QIN Dahe, ${ }^{1}$ ZHANG Dongoi, ${ }^{1}$ REN Jiawen,,${ }^{1}$ KANG Shichang, ${ }^{1,2}$ \\ Paul A. MAYeWSKI, ${ }^{2}$ Gameron P. WAKE ${ }^{3}$ \\ ${ }^{1}$ Laboratory of Ice Core and Cold Regions Environment, Cold and Arid Regions Environmental and Engineering Research Institute, \\ Chinese Academy of Sciences, Lanzhou 730000, China \\ E-mail: shugui@lsce.saclay.cea.fr \\ ${ }^{2}$ Institute for Quaternary and Climate Studies, University of Maine, Orono, ME 04469, U.S.A. \\ ${ }^{3}$ Climate Change Research Center, Institute for the Study of Earth, Oceans and Space, University of New Hampshire, Durham, NH 03824, U.S.A.
}

\begin{abstract}
A $40.9 \mathrm{~m}$ ice core was recovered from Far East Rongbuk Glacier (FER), Qomolangma (Mount Everest), Himalaya, and an $80.4 \mathrm{~m}$ core from neighboring East Rongbuk Glacier (ER). Both are dated by seasonal variations of $\delta^{18} \mathrm{O}$ and major-ionic profiles, together with references of $\beta$-activity peaks. In this paper we compare the chemical records of these two cores to show post-depositional modification processes. The smoothed $\delta^{18} \mathrm{O}$ profiles of the two cores show a similar trend. However, the mean $\delta^{18} \mathrm{O}$ value of the FER core for the period $1954-96$ is $3.12 \%$ less than that of the corresponding part of the ER core, and the major-ionic profiles of the two cores differ considerably. We suggest that melting-away of the snow layer deposited during the pre-monsoon season may account for lower $\delta^{18} \mathrm{O}$ values of the FER than of the ER core, and higher terrestrial ion concentrations in the FER core for the period 1957-63 may contribute to changes by chemical reactions in the presence of snowmelting. The significantly decreased $\mathrm{NH}_{4}{ }^{+}$and, to a lesser degree, $\mathrm{SO}_{4}{ }^{2}$ concentrations in the FER core could be caused by the ion elution process that moved most chemicals away with runoff.
\end{abstract}

\section{INTRODUCTION}

Over the past few years, there has been growing interest in the extraction of paleoclimatic information from chemical profiles measured in high-altitude ice cores (e.g. Koerner, 1997; Grumet and others, 1998). Such valuable ice-core records are, however, usually affected by occasional to moderate melt, which limits their reliability as a means of paleoclimatic reconstruction. More attention should therefore be paid to formation processes of ice-core chemical records from mountainous areas before they can be confidently interpreted as a climatic indicator.

In May and June 1997, a $40.9 \mathrm{~m}$ ice core was recovered from a site at $6500 \mathrm{~m}$ a.s.l. on the north branch of Far East Rongbuk (FER) Glacier, approximately $13 \mathrm{~km}$ north of the peak of Qomolangma (Mount Everest), Himalaya (Fig. 1). Based on field observations of the widely spread dry-stream tracks (the largest snowmelting channel on the surface of the glacier can be several meters wide and $>1 \mathrm{~m}$ deep) and the stratigraphic features of the several snow pits around the FER drilling site, we speculate that the FER core records may be modified by meltwater percolation. In August 1998, another $80.4 \mathrm{~m}$ ice core was recovered from a site at $6500 \mathrm{~m}$ a.s.l. on East Rongbuk (ER) Glacier, $<5 \mathrm{~km}$ north

- Present address: Laboratoire des Sciences de la Terre et de l'Environnement, Laboratoire mixte CEA-CNRS-CE Saclay, 91191 Gif-sur-Yvette, Cedex, France. of Qomolangma peak (Fig. 1). The thickness of the firn layer is $>20 \mathrm{~m}$, and few distinct percolation-ice layers can be identified, implying that little, if any, snowmelt occurs at the ER core drilling site. The stratigraphic features therefore suggest that this drilling site may be located in the cold-percolation or recrystallization zone. In considering potential for post-depositional changes, this makes the ER core a suitable reference in comparisons between the isotopic and ionic profiles of the ER and FER cores.

Sampling and analysis processes for the cores are available elsewhere (Hou and others, 1999b; Qin and other, 2002). Both cores were dated by reference layers of the $\beta$-activity peaks, and seasonal variations in the isotopic and major-ionic $\left(\mathrm{Ca}^{2+}, \mathrm{Na}^{+}\right.$and $\mathrm{NH}_{4}{ }^{+}$) profiles (Fig. 2). In addition, a slight adjustment was made to the FER core dating (Hou and others, 1999b), following a comparison of the chemical concentration peaks of the Lwo cores. Since the same chronological scale is necessary for better comparison of the ice-core records, we confine the time series of the two ice-core records to the periods 1954-96 for the FER core and 1954-97 for the ER core, as determined by the older $\beta$-activity peak. The average sampling resolutions are over 5 and 12 samples a for the above sections of the FER and ER cores, respectively:

\section{2. $\delta^{18} \mathrm{O}$}

The $\delta^{18} \mathrm{O}$ profiles of the ER and FER cores are shown in Figure 3 . The variation of the two $\delta^{18} \mathrm{O}$ profiles is basically similar. especially for the corresponding ridges and troughs of the 


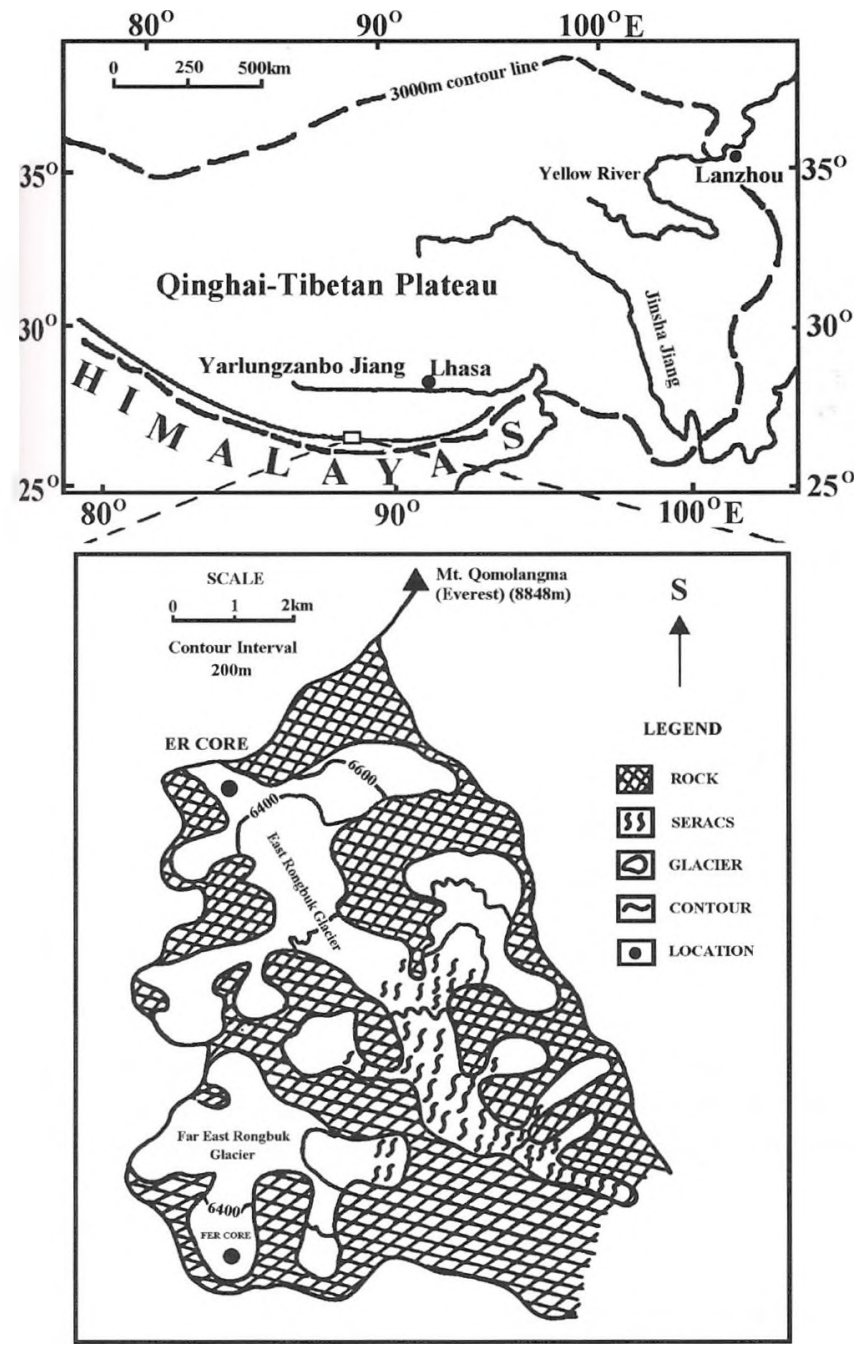

Fig. 1. Location map of ice-core drilling siles.

smoothed lines. For the period 1954-96, the average $\delta^{18} \mathrm{O}$ values of the FER and ER cores are $-20.30 \%$ and - $17.18 \%$, respectively, i.e. different by $3.12 \%$. The fluctuation amplitudes of the two $\delta^{18} \mathrm{O}$ series are similar during the period 1954-86, but that of the FER $\delta^{18} \mathrm{O}$ record decreases rapidly after 1987. Moreover, the $\delta^{18} \mathrm{O}$ gap between the FER and ER cores reaches $4.93 \%$ during the period 1987-96. Since similar processing and analysis procedures are adopted for both cores, the apparent discrepancy is unlikely to be caused by artificial factors.

In western China, $\delta^{18} \mathrm{O}$ in precipitation is mainly controlled by different vapor sources, different transport patterns of vapor in the atmosphere, average "rain-out history" of the air mass, and different temperature structures which control the condensation temperature (Yao and others, 1996; Hou and others, 1999a). In tropical regions (including the cent ral Himalaya), monsoon precipitation has more negative $\delta^{18} \mathrm{O}$ values than precipitation during the other seasons, indicating the amount effect (Kang and others, 1999). Since the two drilling sites are located close together and at the same altitude (6500 $\mathrm{m}$ a.s.l.), the above-mentioned factors do not explain the remarkable discrepancy between the two $\delta^{18} \mathrm{O}$ series of the FER and ER cores. We suggest that this discrepancy may be caused by post-depositional processes, especially the heavy snowmelting that can severely homogenize the original $\delta^{18} \mathrm{O}$ oscillations of the FER core (Hou and others, 1999a). However, the FER core would be expected to show higher $\delta^{18} \mathrm{O}$ values
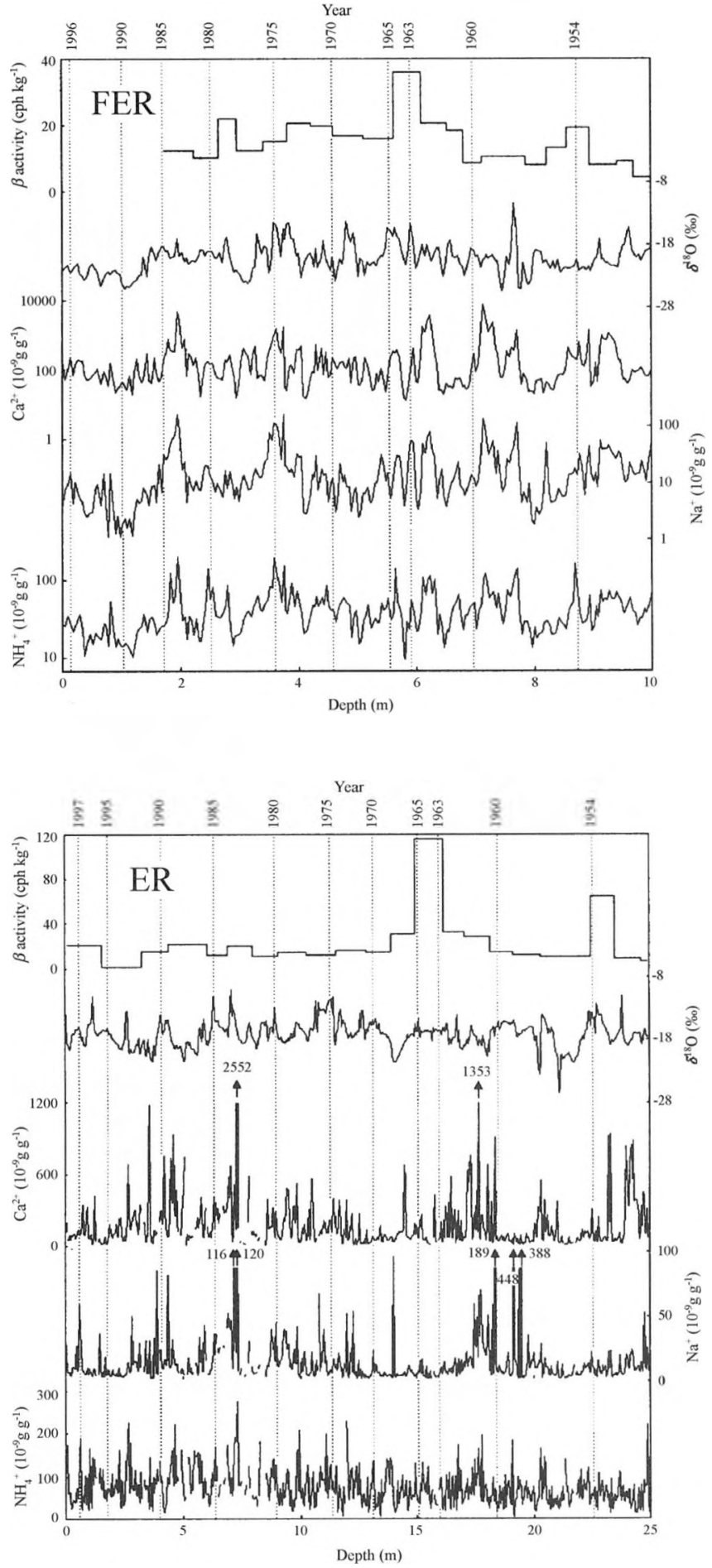

Fig. 2. Ice-core daling. The dashed lines indicate the beginning of each annual layer, and the double $\beta$-activity peaks correspond to the 1954 and 1963 reference annual layers, respectively.

than the ER core due to intensive ablation of the summer snow layer, with low $\delta^{18} \mathrm{O}$ values (amount effect) ( $\mathrm{Kang}$ and others, 1999) at the FER drilling site, which is undoubtedly contrary to the real $\delta^{18} \mathrm{O}$ measurements of the two cores. Therefore, modification by meltwater percolation processes alone does not explain the $\delta^{18} \mathrm{O}$ discrepancy between the two cores.

The uneven seasonal distribution of precipitation can also affect the annual $\delta^{18} \mathrm{O}$ values of the ice cores. For instance, higher mean annual $\delta^{18} \mathrm{O}$ values for the ER core might appear if more winter precipitation (i.e. high $\delta^{18} \mathrm{O}$ values) was accumulated at the ER drilling site than at the FER site. Moreover, surface snow redistribution or blowing-away by wind can also 


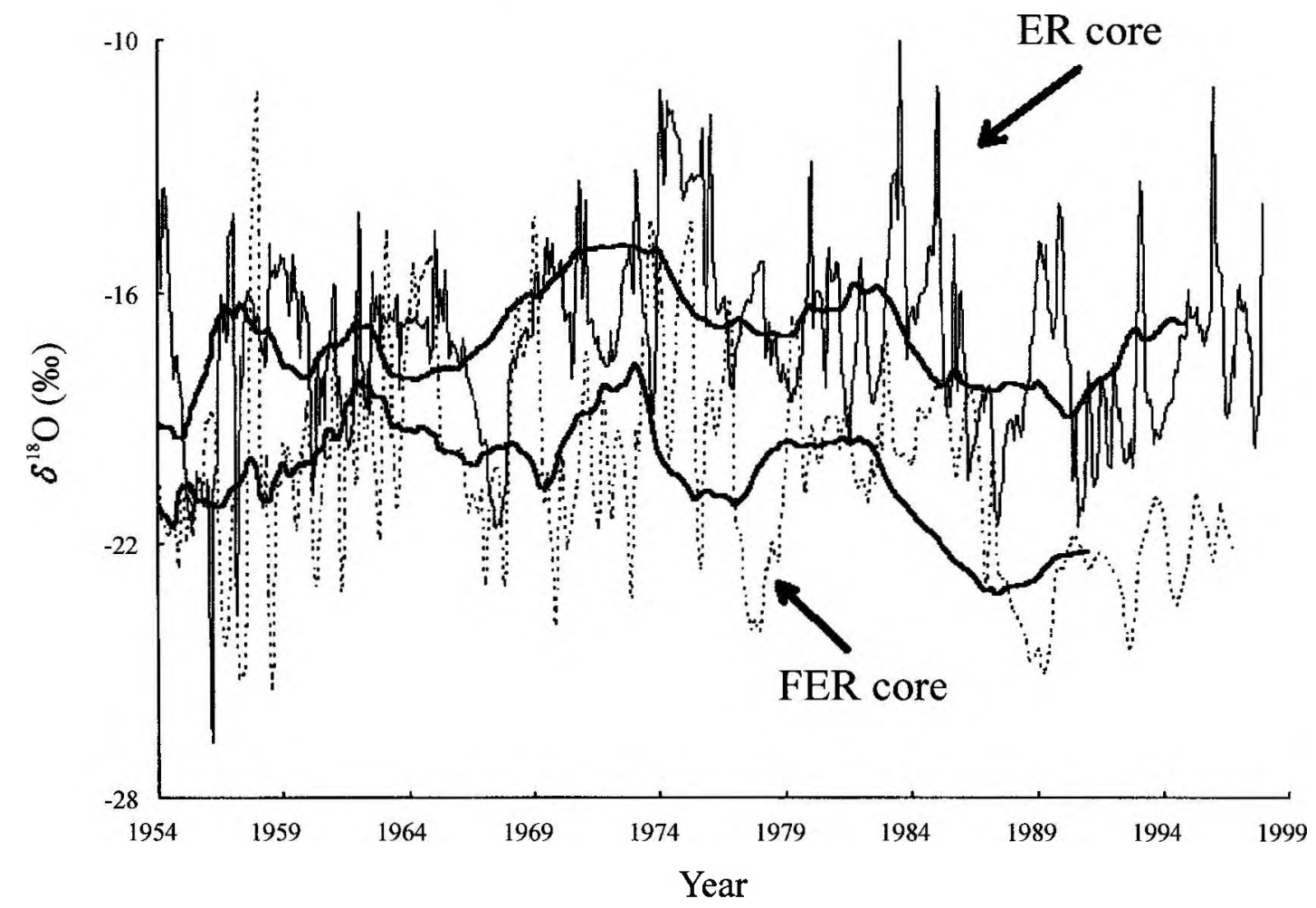

Fig. 3. The $\delta^{18} O$ profiles of the ER core (thin solid line) and FER core (dashed line). The bold lines stand for the 46-point smoothing result for the ER core and the 20-point smoothing result for the FER core, respectively. Both smoothing results are approximately equal to 4 a moving averages. The smoothed FER record does not cover the years 1989-94 due to the smoothing method used.

influence the final $\delta^{18} \mathrm{O}$ values of the ice cores. Year-round field observation at the ice-core drilling sites is planned in order to determine the factors controlling the ice-core $\delta^{18} \mathrm{O}$ records, as well as to establish the relationship between the various icecore records and atmospheric parameters.

\section{MAJOR IONS}

The major-ionic profiles of the ER and FER cores are shown in Figure 4. Considerable differences between corresponding ionic profiles of the two cores are apparent. The concentrations of $\mathrm{Ca}^{2+}, \mathrm{Mg}^{2+}, \mathrm{SO}_{4}{ }^{2-}$ and $\mathrm{NO}_{3}{ }^{-}$for the FER core are higher than for the ER core before 1985, but much lower since then. Differences can also be observed for the $\mathrm{Cl}, \mathrm{Na}^{+}$and $\mathrm{K}^{+}$profiles. $\mathrm{NH}_{4}{ }^{+}$concentrations are significantly lower for the FER core than for the ER core; the mean $\mathrm{NH}_{4}{ }^{+}$concentration of the FER core since 1985 is only one-quarter of that of the ER core.

The average net accumulation rate of the FER core is less than half of that of the ER core for the period 1954-96 (Qin and others, 2002; Fig. 2). To eliminate the effect of the varied accumulation rate on concentrations, we calculate the flux $(F)$ of each chemical species by the equation $F=C A$, where $C$ is the individual annual mean concentration and $A$ is the annual accumulation rate. The chemical fluxes of the two cores are compared in Figure 5. For $\mathrm{Ca}^{2+}$, $\mathrm{Mg}^{2-}$ and, to a lesser degree, $\mathrm{NO}_{3}{ }^{-}$, the chemical fluxes of the FER core are higher than those of the ER core before 1963, but much lower after 1985, while similar flux values can be observed during the period 1964-84. Except for a few small intervals, the chemical fluxes of $\mathrm{Gl}^{-}, \mathrm{Na}^{+}, \mathrm{K}^{+}$ and $\mathrm{SO}_{4}{ }^{2-}$ in the FER core tend to be lower than in the ER core. Moreover, the fluxes of $\mathrm{NH}_{4}^{+}$in the FER core are always lower than in the ER core.

The phasing of the gaps between the neighboring flux peaks of the two cores (Fig. 5) may reflect the real variations, but it may also be caused by the potential error in the icecore dating. Therefore, we further calculate the cumulative flux of each chemical species since 1954 (the older $\beta$-activity horizon), as shown in Figure 6 . The cumulative $\mathrm{Ca}^{2+}, \mathrm{Mg}^{2+}$ and $\mathrm{NO}_{3}{ }^{-}$fluxes indicate a sharp increase during the period 1958-61 for the FER core against the ER core, but this increase has slowed down since the mid-1980s while the cumulative $\mathrm{Ca}^{2+}, \mathrm{Mg}^{2+}$ and $\mathrm{NO}_{3}$ fluxes of the ER core have continued increasing. As a result, the final cumulative $\mathrm{Ca}^{2+}$ and $\mathrm{NO}_{3}{ }^{-}$fluxes are very similar, and the gap between the cumulative $\mathrm{Mg}^{2+}$ fluxes of the two cores has narrowed since the mid-1980s. The cumulative fluxes of all the other major ions $\left(\mathrm{NH}_{1}{ }^{+}, \mathrm{SO}_{1}{ }^{2}, \mathrm{Cl}^{-}, \mathrm{Na}^{+}\right.$and $\left.\mathrm{K}^{+}\right)$are lower in the FER core than in the ER core. For instance, the final cumulative $\mathrm{NH}_{4}{ }^{+}$flux of the FER core is $335.2 \mathrm{~kg} \mathrm{~km}^{-2} \mathrm{a}^{-1}$, less than onethird of that of the ER core $\left(1232.2 \mathrm{~kg} \mathrm{~km}^{-2} \mathrm{a}^{-1}\right.$ in 1996).

The apparent discrepancy in the ionic concentrations and fluxes of the two cores cannot be caused by depositional processes (e.g. different atmospheric loadings at the two drilling sites). Previous studies have shown that $50-80 \%$ of the pollutant load in the snowpack can be released with the first $30 \%$ of the snowmelting (Johannessen and Henriksen, 1978; Tranter and others, 1986). Thus the ion-elution process can leach most of the ions from the uppermost part of the snowpack. The concentrated meltwater moves downwards, then refreezes on the underlying stratigraphic discontinuity location, resulting in ice lenses or ice layers with high ionic concentrations. However, most of the ions can flow away from the glacier system with the snowmelt discharge. If 

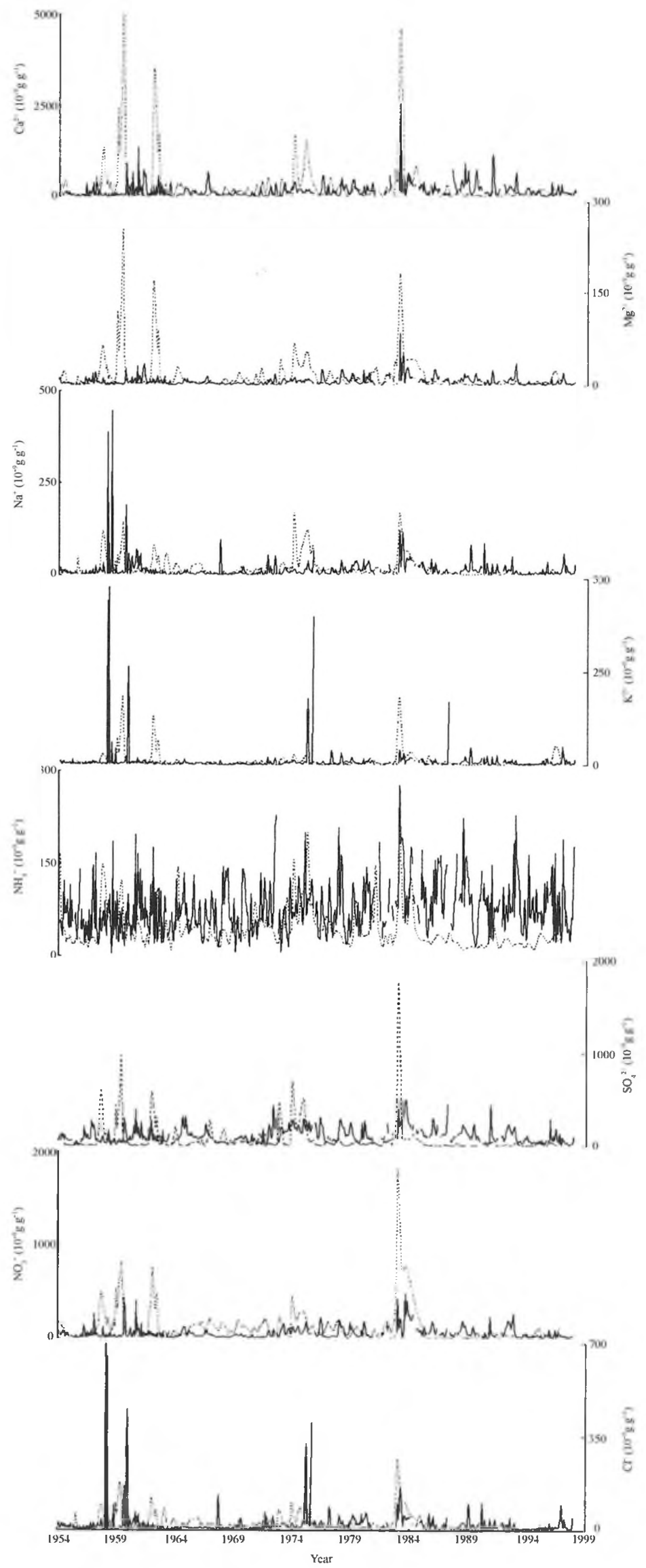

Fig. 4. The ionic profiles of the ER core (solid lines) and the FER core (dashed lines).

more intensive melting follows, this results in glacier ice layers with very low ionic contents (Hou and others, 1996; Hou and Qin, 1999). Though the distance between the FER and ER core drilling sites is only a few kilometers, the average net accumulation rate at the FER core site is less than half that at the ER core site, suggesting a higher ablation 

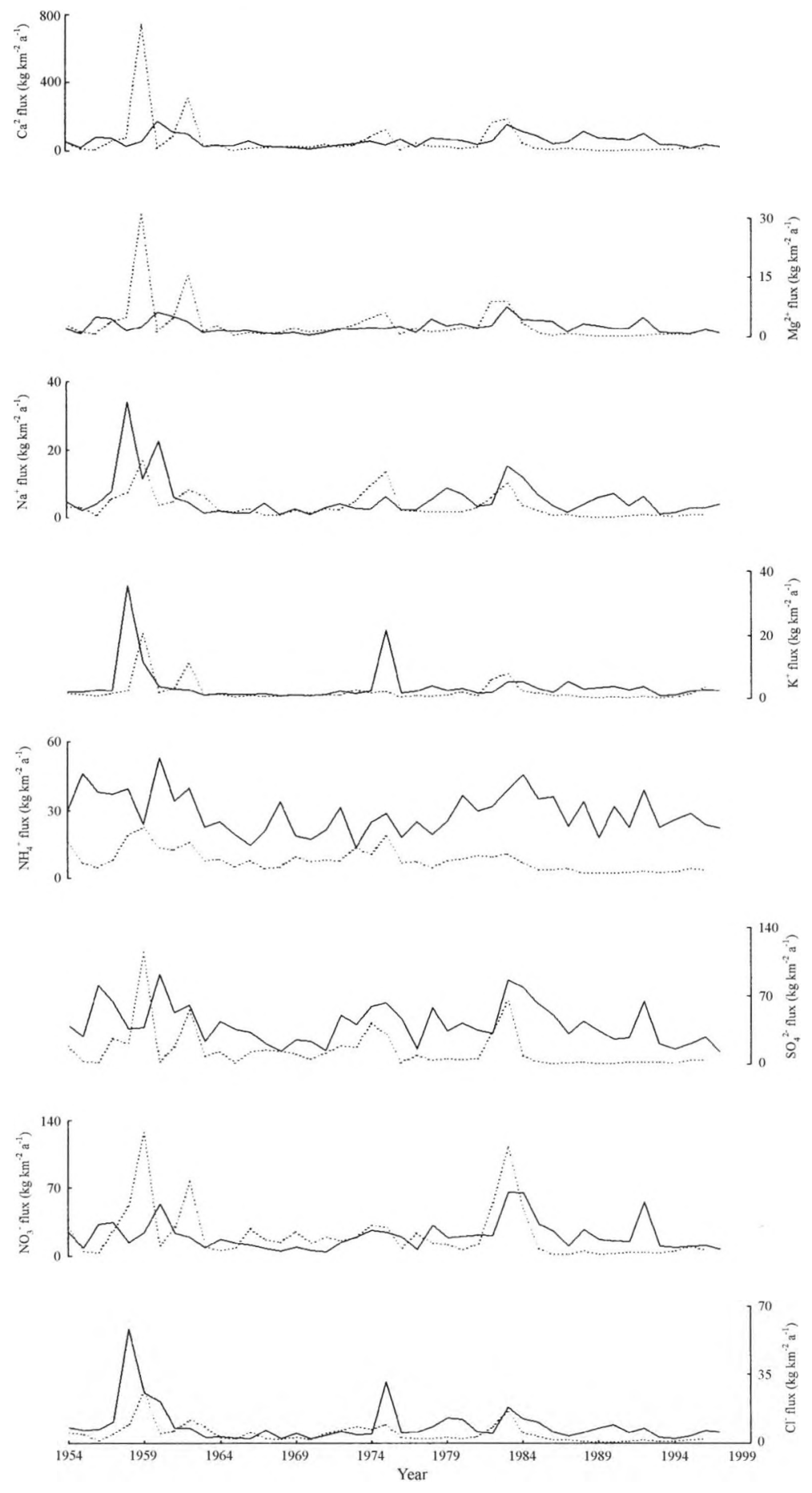

Fig. 5. The annual fluxes of each chemical species for the ER core (solid lines) and the FER core (dashed lines).

rate at the FER than at the ER core site. Field observation also confirmed heavy snowmelting, mostly in late summer on the south-facing FER Glacier, compared with little or no snowmelting at the ER corc drilling site. Thus we suggest that the low chemical loads for $\mathrm{NH}_{4}{ }^{+}, \mathrm{SO}_{4}{ }^{2}, \mathrm{Cl}, \mathrm{Na}^{+}$and $\mathrm{K}^{+}$in the FER core may be attributable to chemical release by the ion-elution process.

Both field and laboratory observations suggest that $\mathrm{SO}_{4}{ }^{2-}$ and $\mathrm{NH}_{4}{ }^{+}$might be preferentially leached by meltwater (Tranter and others, 1986), which may explain the large difference between the final cumulative $\mathrm{SO}_{4}{ }^{2-}$ and $\mathrm{NH}_{4}{ }^{+}$fluxes of the $t$ wo cores. Though $\mathrm{Ca}^{2+}$ is also preferentially eluted from the snow and ice, several chemical reactions in the presence of meltwater probably contribute a certain quantity of $\mathrm{Ca}^{2+}$ (Hasnain and Thayyen, 1999), such as carbonation reactions involving atmospheric $\mathrm{CO}_{2}$ :

$$
\begin{aligned}
& \mathrm{CaCO}_{3} \text { (calcite) }+\mathrm{CO}_{2}+\mathrm{H}_{2} \mathrm{O}=\mathrm{Ca}^{2+}+2 \mathrm{HCO}_{3}^{-} \\
& \mathrm{CaAl}_{2} \mathrm{Si}_{2} \mathrm{O}_{8}\left(\mathrm{Ca} \text {-feldspar) }+2 \mathrm{CO}_{2}+2 \mathrm{H}_{2} \mathrm{O}\right. \\
& =\mathrm{Ca}^{2+}+2 \mathrm{HCO}_{3}^{-} \\
& \quad+\mathrm{H}_{2} \mathrm{Al}_{2} \mathrm{Si}_{2} \mathrm{O}_{8} \text { (partially weathered feldspar) }
\end{aligned}
$$

or coupled reactions involving the weathering of carbonates by protons derived from sulphide oxidation:

$4 \mathrm{FeS}_{2}$ (pyrite) $+16 \mathrm{CaCO}_{3}$ (calcite) $+15 \mathrm{O}_{2}+14 \mathrm{H}_{2} \mathrm{O}$

$$
=16 \mathrm{Ca}^{2+}+16 \mathrm{HCO}_{3}^{-}+8 \mathrm{SO}_{1}^{2-}+4 \mathrm{Fe}(\mathrm{OH})_{3} \text {. }
$$

Thercfore, the $\mathrm{Ca}^{2+}$ supplement for the FER core may roughly 

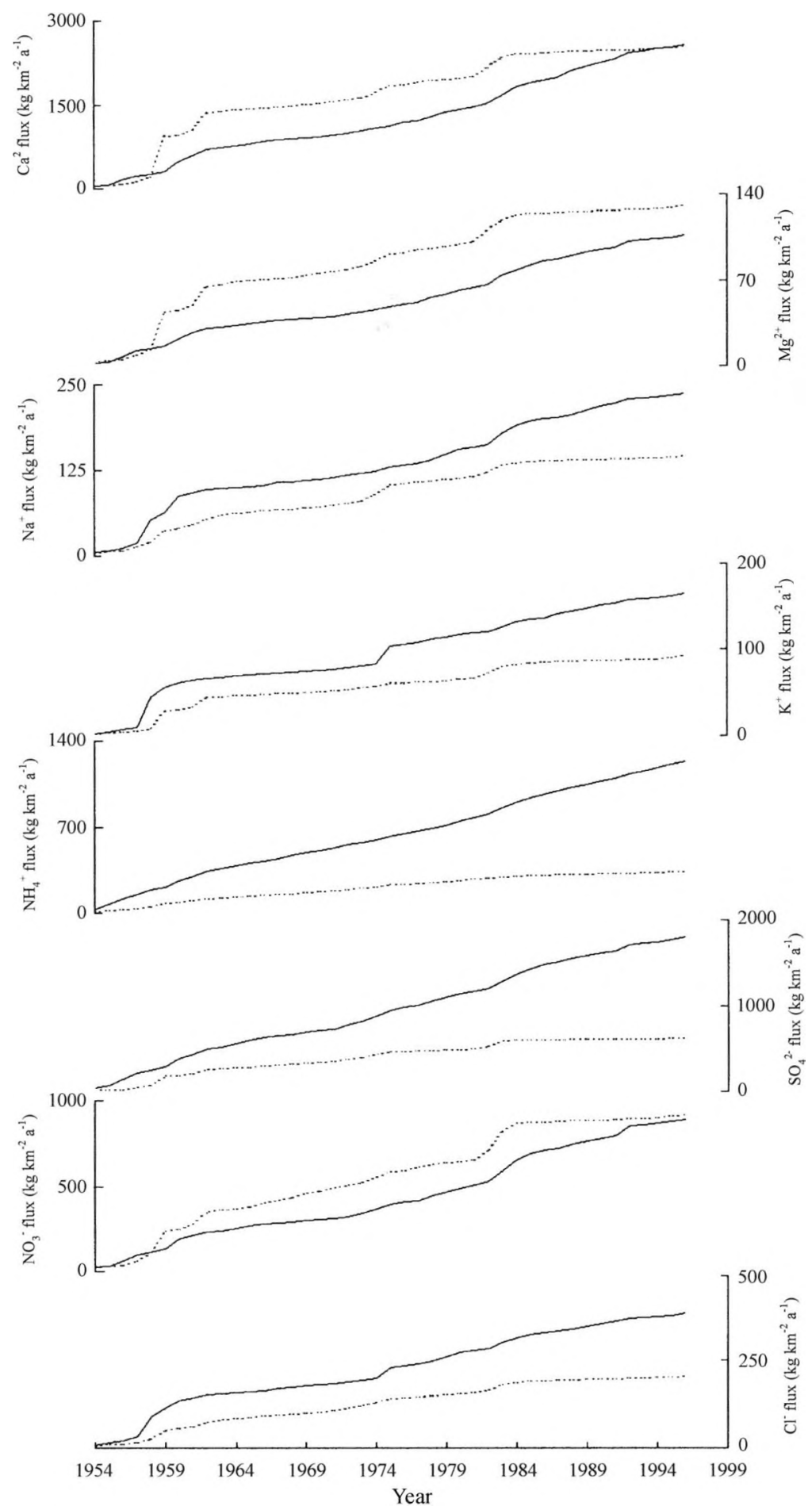

Fig. 6. The cumulative fluxes of each chemical species for the ER core (solid lines) and the FER core (dashed lines).

offset the amount lost by the ion-elution process, and Reaction (3) should play a minor role, given the extremely low cumulative $\mathrm{SO}_{4}{ }^{2}$ flux of the FER core.

$\mathrm{NO}_{3}{ }^{-}$is also very active during the elution process, so the similar cumulative $\mathrm{NO}_{3}$ fluxes of the two cores imply that it is supplemented in the FER core by chemical reaction(s). Lyons and others (1990) report that crustally derived $\mathrm{NO}_{3}$ from soils appears to be the main source of $\mathrm{NO}_{3}{ }^{-}$in snow samples from central Asia. Williams and others (1992) carried out comprehensive research into the sources and spatial variation of the chemical content of winter snow pack at the head of the Urümqi river, and confirmed that terrestrial dust may be the primary source of $\mathrm{NO}_{3}$ in the snowpack. As for $\mathrm{Ca}^{2+}$, we speculate that a similar chemical process might occur for
$\mathrm{NO}_{3}$ in the FER core, although much work needs to be done to obtain details of the potential chemical reactions.

\section{CONCLUSIONS}

Through comparison of two adjacent ice-core chemical records, it is suggested that the overall characteristics of the $\delta^{18} \mathrm{O}$ profiles of the two cores are similar, while a significant discrepancy exists for the ionic profiles of the two cores due to the elution process and chemical reactions. Therefore, the ice-core records are affected not only by the climatic and environmental conditions during precipitation, but also by the post-depositional processes. If ice cores, especially those 
recovered from less than ideal environments, are to be used with confidence for paleo-reconstruction, it is first necessary to determine how much the records reflect the climatic and environmental conditions, and which records are just modified results of post-depositional processes.

Recent glacier retreat and thinning have been widely observed in the high mountains, and rising temperatures are expected 10 intensify this trend. Therefore, our results also suggest an urgent need to recover valuable ice cores from high elevations before they are completely washed out.

\section{ACKNOWLEDGEMENTS}

We thank S. I. Whitlow for chemical measurements of the samples. This rescarch was supported by the Chinese Academy of Sciences (KZCX1-10-02; KZCX2-301; KZCX2-108); the Cold and Arid Regions Environmental and Engineering Research Institute (CACX210506); the K. C. Wong Foundation, Centre National de la Recherche Scientifique, France; and the National Natural Science Foundation of China (49901004, 49871022). The manuscript was improved by comments from T. van Ommen, I. D. Goodwin and an anonymous reviewer.

\section{REFERENCES}

Grumet, N. S., C. P. Wake, G. A. Zielinski, 1). Fisher, R. Koerner and J. I). Jacobs. 1998. Preservation of glaciochemical time-series in snow and ice from the Penny Ice Cap, Baffin Island. Geophys. Res. Lett., 25(3), 357-360.

Hasnain, S. I. and R. J. Thayyen. 1999. Controls on the major-ion chemistry of the Dokriani glacier meltwaters, Ganga basin, Garhwal Himalaya,
India. F. Glaciol., 45(149), 87-92.

Hou Shugui and Qin Dahe. 1999. TThe ion elution effect on the main ion profiles of the glacier snowpacks.] / Chinese 7. Geogr. Sci.), 19(6), 536-542. [In Chinesc with English summary.]

Hou Shugui, Qin Dahe and Huang Guilan. 1996. [The clution of ions in twe snow pits in the Dongkemadi glacier area, Tiznggula Range. 7. Glaciol. Geocryol., 18(3), 227-234. [In Chincse with English summary.]

Hou Shugui and 6 others. 1999a. Climatological significance of $\delta^{18} \mathrm{O}$ in precipitation and icc cores: a case study at the head of the Urümqi river. Tien Shan, China. J. Glaciol, 45(151), 517-523.

Hou Shugui, Qin Dahe, C. P. Wake and P. A. Mayewski. 1999b. Correspondence. Abrupt decrease in recent snow accumulation at Mount Qomolangma (Everest), Himalaya. 7. Glaciol., 45(151), 585- 586.

Johamnessen, M. and A. Henriksen. 1978. Chemistry of snow meltwater: changes in concentration during melting. Water Res. Res., 14 (4), 615-619.

Kang Shichang, Qin Dahe, Yao Tandong, C. P. Wake and P. A. Mayewski. 1999. [Summer monsoon and dust signals recorded in Dasuopu firn core, Mt. Xixiabangma.] / ('him. Sci. Bull.), 44(22), 2230-2235. [In Chincse.]

Koerner, R. M. 1997. Some comments on climatic reconstructions from ire cores drilled in areas of high melt. 7. Glaciol., 43(143), 90-97. (Erratum: 43 (144), p. 375-376.)

Iyons, W. B., P. A. Mayewski, M. J. Spencer and M. S. Twickler. 1990. Nitrate concentrations in snow from rcmotc arcas: implications for the global $\mathrm{NO}_{\mathrm{Y}}$ flux. Biogeochemistry, 9(2), 2ll-222.

Qin Dahe and 6 others. 2002. Preliminary results from the chemical records of an $80.4 \mathrm{~m}$ ice core recovered from East Rongbuk Glacier, Qomolangma (Mount Everest), Himalaya. Ann. Glaciol, 35 (sec paper in this volume).

Tranter, M., P. Brimblecombe, T. R. Davics, C. E. Vincent, P. W. Abrahams and I. Blackwood. 1986. The chemical composition of snowpack, snowfall and melewater in the Scottish Highlands - evidence for preferential clution. Aimos. Environ., 20(3), 517-525.

Williams, M.W., K. A. Tonnessen, J. M. Melack and Yang Daqing. 1992. Sources and spatial variation of the chemical composition of snow in the Tien Shan, China. Ann. Glaciol, 16, 25-32.

Yao Tandong, I. G. Thompson, E. Mosley-Thompson, Yang Zhihong, Zhang Ximping and Lin Ping-Nan. 1996. Climatological significance of $\delta^{18} \mathrm{O}$ in north Tibetan ice cores. 7. Geophys. Res., 101 (I)23), 29,531-29,538. 